\title{
Localized Pigmented Villonodular Synovitis in a Child: About a Case
}

\author{
Meryam Ramzi ${ }^{1}$, Nada Assara ${ }^{1}$, Zakarya Alami Hassani ${ }^{1 *}$, Zouhir Alami Fellouss ${ }^{2}$, Tariq Madhi ${ }^{2}$
}

${ }^{1}$ Resident Doctor, Department of Pediatric Traumatology and Orthopedics, Children's Hospital of Rabat, Ibn Sina UHC / Mohammed

V University, Faculty of Medicine and Pharmacy, Rabat, Morocco

${ }^{2}$ Professor of Higher Education, Department of Pediatric Traumatology and Orthopedics, Children's Hospital of Rabat, Ibn Sina UHC / Mohammed V University, Faculty of Medicine and Pharmacy, Rabat, Morocco

DOI: $\underline{10.36347 / \mathrm{sasjs} .2022 . \mathrm{v} 08 \mathrm{i} 01.006}$

| Received: 10.08.2021 | Accepted: 14.09.2021 | Published: 16.01.2022

*Corresponding author: Zakarya Alami Hassani

Resident Doctor, Department of Pediatric Traumatology and Orthopedics, Children's Hospital of Rabat, Ibn Sina UHC / Mohammed V University, Faculty of Medicine and Pharmacy, Rabat, Morocco

\section{Abstract}

Pigmented Villonodular synovitis (PVNS) is a rare benign proliferative condition affecting synovial membranes of joints; it occurs in two forms, localized (LPVNS) and diffuse (DPVNS). We report a case of a 12 years old with LPVNS, confirmed on surgical biopsy. The patient underwent a surgical synovectomy, with good evolution after 1 year follow-up. PVNS is most common in early to middle age, It still exceptional in children. Clinically, its symptology remains aspecefic. This is often a cause of delay in diagnosis. Magnetic resonance imaging (MRI) is the exam of choice. Only a synovial biopsy with histological study confirms the diagnosis; the treatment typically involves surgery: synovectomy, with a risk of recurrence.

Keywords: Vilonodularsynovitis, localized form, child, synovectomy.

Copyright $(\odot) 2022$ The Author(s): This is an open-access article distributed under the terms of the Creative Commons Attribution 4.0 International License (CC BY-NC 4.0) which permits unrestricted use, distribution, and reproduction in any medium for non-commercial use provided the original author and source are credited.

\section{INTRODUCTION}

PVNS is a benign tumor of the synovium with strong proliferation and an aggressive invasion. Its cause is still unknown. It is most common in young adults and usually affects the knee. Symptoms might include: pain, limitation of movement, and locking of the joint. In some cases, the normal joint structure can be destroyed. Treatment involves surgery to remove the tumor and damaged portions of the synovium. The LPVNS is the least frequent form and responds well to surgery with a low rate of recurrence.

\section{CASE REPORT}

It is a 12-year-old boy who presented with pain and edema of the right knee that has been evolving for 2 years with the onset of functional impotence. The XRay imaging was normal, an ultrasound of the knee showed a nodular hypertrophy of the synovium of the antero medial compartment (Figure 1).

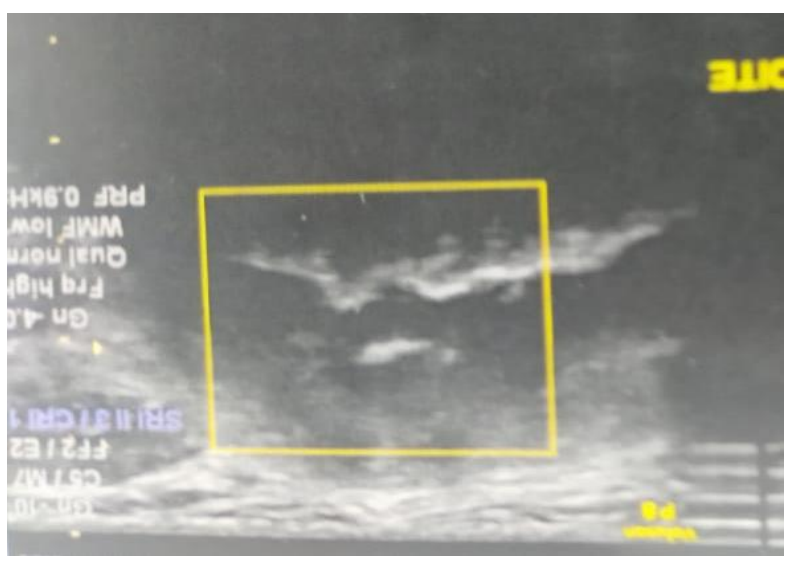

Figure 1: An ultrasound of the knee showing a nodular hypertrophy of the synovium of the antero medial compartment

The MRI showed a synovial process in lowsignal T1 and T2, measuring 50 / 30mm with hematic joint effusion (Figure 2). 
Meryam Ramzi et al., SAS J Surg, Jan, 2022; 8(1): 20-21

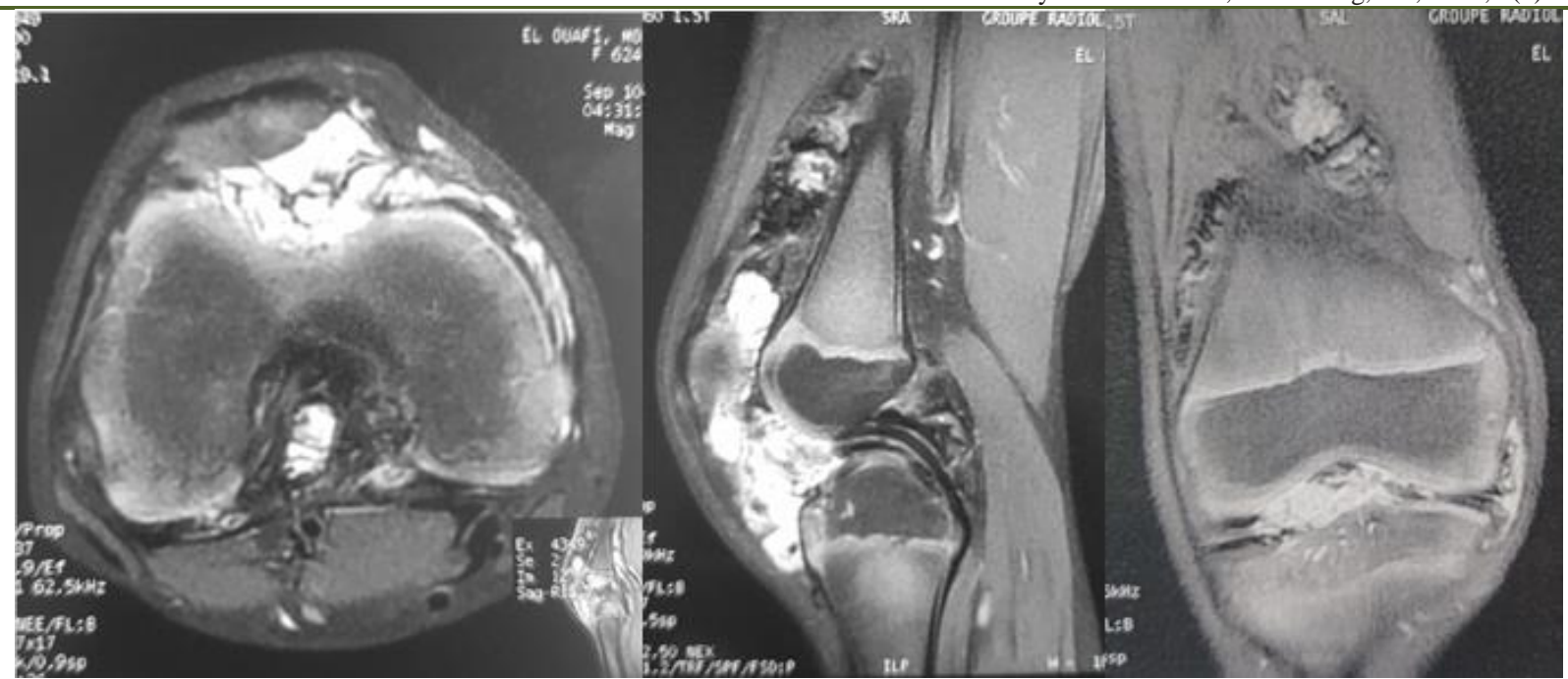

Figure 2: MRI showing a synovial process in lowsignal T1 and T2, measuring 50 / 30mm with hematic joint effusion

The fluid from the joint aspiration was hematic. The patient underwent an open synovial biopsy, which confirmed the diagnosis. A surgical synovectomy was performed. After One year follow-up, there is no evidence of recurrence, and the patient is asymptomatic.

\section{DISCUSSION}

PVNS was first described in 1852. Its etiology is uncertain. The estimated incidence is around 1.8 per million. It frequently affects young adults, only few cases are reported in the pediatric population, usually only one joint is affected: the knee $(70 \%)$ followed by the hip and ankle. Diagnosis is often delayed or confused with other pathology

DPVNS seems to be the most frequent (90\%) with a high recurrence rate, while the LPVNS responds perfectly to surgical treatment with a recurrence risk around $20 \%$. There are reports in the literature that PVNS may be of neoplastic nature.

Its clinical evolution is a slow and insidious onset of pain, swilling and stiffness in the involved joint. The $\mathrm{x}$ ray can show degenerative signs. The joint ultrasound highlights synovial thickness. The MRI remains the imaging of choice with typically a hyposignal in $\mathrm{T} 1$ and $\mathrm{T} 2$ due to the deposition of hemosiderin.

Biopsy by arthroscopy or surgery is necessary to confirm the diagnosis. The treatment depends on the form of PVNS.

LPVNS is rare with low rates of recurrence after synovectomy which is this form's treatment of choice.
DPVNS has more reserved prognosis mainly due to its recurrent character, but surgery remains the main therapy in DPVNS associated with synoviorthesis, curitherapy, and external beam radiation.

It is necessary to khow that there is no clinical, radiological or therapeutical, specificity in children.

\section{CONCLUSION}

PVNS is a rare pathology of children. In case of clinical suspicion, the MRI is the method of choice, synovial biopsy comfirms the diagnosis,thetraitment is simple in the LPVNS, only a synovectomy is indicated with a low rate of recurrence

Recent advances in undertanding the physiopatholology and use of physiopathology and the use of molecules targeting cell proliferation could change the prognosis of the DPVNS.

\section{REFERENCES}

- Ramos, M. A., Balsini, N. E., Ramos, F., \& Machado, L. G. (2016). Arthroscopic surgical treatment of pigmented villonodular synovitis of the elbow: case report. Revista Brasileira de Ortopedia (English Edition), 51(4), 478-481.

- Legré, V., Boyer, T., Dorfmann, H., \& Lafforgue, P. (2007). Tumeurs et dystrophies de la synoviale. EMC Appareil locomoteur. Paris: Elsevier Masson SAS, 6-8.

- Jaffe, H. L. (1941). Pigmented villonodular synovitis, bursitis and tenosynovitis. Arch Pathol, 31, 731-765.

- Garner, H. W., Ortiguera, C. J., \& Nakhleh, R. E. (2008). Pigmented villonodular synovitis. Radiographics, 28(5), 1519-1523. 